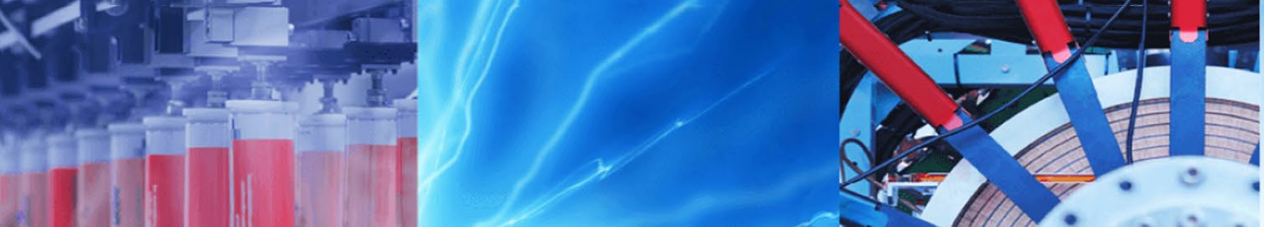

Research Article

\title{
Effect of the water depth on the hydrogen content in SMAW wet welded joints
}

\author{
Jan Klett ${ }^{1}$ (1) $\cdot$ Vitali Hecht-Linowitzki $^{1} \cdot$ Oliver Grünzel ${ }^{1} \cdot$ Emily Schmidt $^{1} \cdot$ Hans Jürgen Maier $^{1} \cdot$ Thomas Hassel $^{1}$
}

Received: 5 February 2020 / Accepted: 12 June 2020 / Published online: 23 June 2020

(C) The Author(s) 2020 OPEN

\begin{abstract}
Hydrogen-induced cold cracking is a huge challenge in underwater wet welding. In the present study, the influence of water depth on the diffusible and residually stored hydrogen content is investigated for the case of underwater wet shielded metal arc welding. The welding is carried out in a simulated water depth of 5, 20, 40, and $60 \mathrm{~m}$ with four stick electrodes specifically developed for underwater wet welding. The influence of the welding current, the arc voltage and the electrode's composition on the diffusible hydrogen content are considered. To obtain reproducible welding conditions, a fully automated multi-axis welding system is used inside a pressure chamber. The water depth is simulated by setting the internal pressure up to 6 bar, equivalent to $60 \mathrm{~m}$ water depth. A large amount of samples are analysed and statistical method are used to evaluate the results. The results show a significant reduction of the diffusible hydrogen and an increase of residual hydrogen in the joining zone with increasing water depth.
\end{abstract}

Keywords Wet welding · Diffusible hydrogen · Residual hydrogen · Shielded metal arc welding (SMAW) · Hydrogen induced cracking (HIC) - Water depth

\section{Introduction}

Hydrogen induced cracks are the main risks in underwater wet welding since they may occur delayed, up to weeks after welding. Their cause is a complex interaction of three factors [1-3], i.e.

- the diffusible hydrogen content

- the loading condition (including residual stresses)

- the materials microstructure.

In wet welding (i.e. direct contact of electrode and workpiece with the surrounding water), all these risk factors can be found collectively. The high energy of the electric arc leads to dissociation of water into molecular hydrogen and oxygen. In the arc column the hydrogen is dissociated and ionized. It returns to the atomic state in the colder arc areas and on the surface of the liquid metal. These conditions promote hydrogen diffusing into the weld metal. The gas bubble surrounding the arc can contain up to $92 \%$ hydrogen [4]. The materials commonly used in the offshore industry are ferritic-perlitic steels. In these steels atomic hydrogen is able to diffuse rapidly even below room temperature [3]. The high cooling rates in the wet welding process promote high hardness in the heat affected zone (HAZ). This hardness usually rises with increasing yield strength, making higher strength steel prone to failure [5]. In addition, constrained welding shrinkage results in residual stresses. Thus, even without external load, the weld seam presents a risk of failure.

In dry welding preheating methods are used to lower the HIC risk in higher strength steel by prolonging the critical cooling time of the weldment $\left(t_{8 / 5}\right)$ [6]. In wet welding, no preheating method could be established yet. The only

Jan Klett, klett@iw.uni-hannover.de | 'Institut für Werkstoffkunde, Leibniz Universität Hannover, An der Universität 2, 30823 Garbsen, Germany. 
practically used method to weld higher strength steel in wet conditions is the temper bead technique, where every weld bead is covered by a second temper bead [7-10]. This bead tempers the HAZ of the first weld bead and should later be removed by grinding. Other methods to deal with the risk of HIC have been investigated in multiple studies, but are so far not widely used by divers. A possible ways to address the challenge of high hydrogen content in wet weldments is the alteration of the stick electrode's cover $[11,12]$. The alteration of the core wire was tried, too. An addition of austenitic filler material to trap the diffusible hydrogen was investigated by different researchers and shows high potential [13-16]. Another promising approach is the usage of induction technology as an underwater pre-, simultaneous- and/or post-heating method [17-19].

Additionally to lowering the HIC risk, many studies focus on gaining a more detailed understanding of the influences on the hydrogen content in wet welding. Recent research has focused on describing the effects of hydrogen on the behavior of underwater welded seams. Influences investigated are the arc length (welding voltage), the welding current, the welding speed and the salinity of the water [20]. According to Świerczyńska, Fydrych, and Rogalski, an increase in the arc length, welding current, and salinity of water lead to lower diffusible hydrogen contents, while a faster welding speed increases the diffusible hydrogen content in the weld metal. It is not expected that the hydrogen content of ferritic structural steel can be reduced below $21 \mathrm{ml} / 100 \mathrm{~g}$ in the case of underwater FCAW wet welding [20].

The influence of water depth was first described in 1983 by Ando and Asahina [21] and more recently by da Silva, Ribeiro, Bracarense and Pessoa in 2012 [22]. Ando et al. showed a decreasing diffusible hydrogen content from 0.3 to $100 \mathrm{~m}$ of water depth for 4 different electrodes. Da Silva et al. also showed a negative correlation between diffusible hydrogen contents and water depth. They furthermore analysed the residual hydrogen contents and found no difference in the results for water depths varying from 0.3 to $30 \mathrm{~m}$. The diffusible hydrogen content seemed to reach a plateau at $30 \mathrm{~m}$ water depths. This difference to the work of Ando et al. could be caused by the usage of different hydrogen measuring methods. Ando et al. used the glycerin method while da Silva et al. used gas chromatography [21,22]. Both works used the mechanized gravity welding method inside of pressurized chambers. Neither work states the time span between welding and cooling/ analysis. This is an important factor, as the diffusion of hydrogen will continue after welding, until the sample is cooled down to stop diffusion processes. Without immediate cooling, part of the hydrogen can leave the material and will not be measured as diffusible hydrogen [23]. The usage of gravity welding adds the risk of misjudging influences, since the arc voltage cannot be controlled during the welding process, and might thus be influenced by the water depth.

Until flux cored wires and the necessary equipment (e.g. wire feeding) for wet welding are commercially available, the wet shielded metal arc welding process will probably stay the most relevant underwater welding process. The advantages are huge and the possibilities to advance the weld quality might be huge as well, as the understanding of the process grows. In the present study, the influence of the water depth, arc voltage, welding current and stick electrode composition on the hydrogen content of underwater wet welded samples were analysed. An arc voltage controlled welding machine and a newly developed system for hydrogen analyses were used. The experimental setup can meet the time specifications of the standard ISO 3690 , regardless of the investigated water depth. Since large variances in the diffusible hydrogen contents were expected, a large number of samples was investigated and analysed using statistical methods. In Sect. 2 the experimental setup and the procedures are explained. Section 3 shows the results and Sect. 4 discusses them in detail.

\section{Materials and methods}

\subsection{Experimental set up}

Experiments were performed in a hyperbaric chamber with $10 \mathrm{~m}^{3}$ inner volume, customized for underwater wet welding (Fig. 1).

The chamber can be filled with fresh- or saltwater and is approved for up to 30 bar internal pressure, resulting in simulated water depths ranging from 0.5 to $300 \mathrm{~m}$. Inside the chamber, there is a unique multi-axis welding machine consisting of a 3 -axes portal ( $x, y$ and $z$ linear axis) as well as a rotation and tilt manipulator holding the welding- and cleaning unit. Wet weldments are carried out by controlling the arc length through the arc voltage, using a PIDcontroller. A revolving magazine, storing up to 100 stick electrodes, was implemented into the chamber to provide dry electrodes for a fully automated welding process. A system to measure the actual arc voltage and welding current during the welding process is also included.

In order to determine the diffusible hydrogen content in wet weldments, a manipulator system was developed, build and installed within the chamber (Fig. 1a, b). The system consist of five levers holding each up to three welding-samples. Since this is not in accordance with ISO 3690 [23], which does not recommend three samples, a correlations test between the position of the samples (first, second, or third to be welded) and their hydrogen content 
Fig. 1 Inside view of the $10 \mathrm{~m}^{3}$ welding chamber used for wet welding. Included is a system for the weldment of hydrogen samples based on ISO 3690. a Insulated tank containing 0.2 $\mathrm{m}^{3}$ of liquid nitrogen, $\mathbf{b}$ clamping system for five samples according to ISO 3690-sample geometry $\mathrm{C}$, $\mathrm{c}$ welding axis with the electrode holder

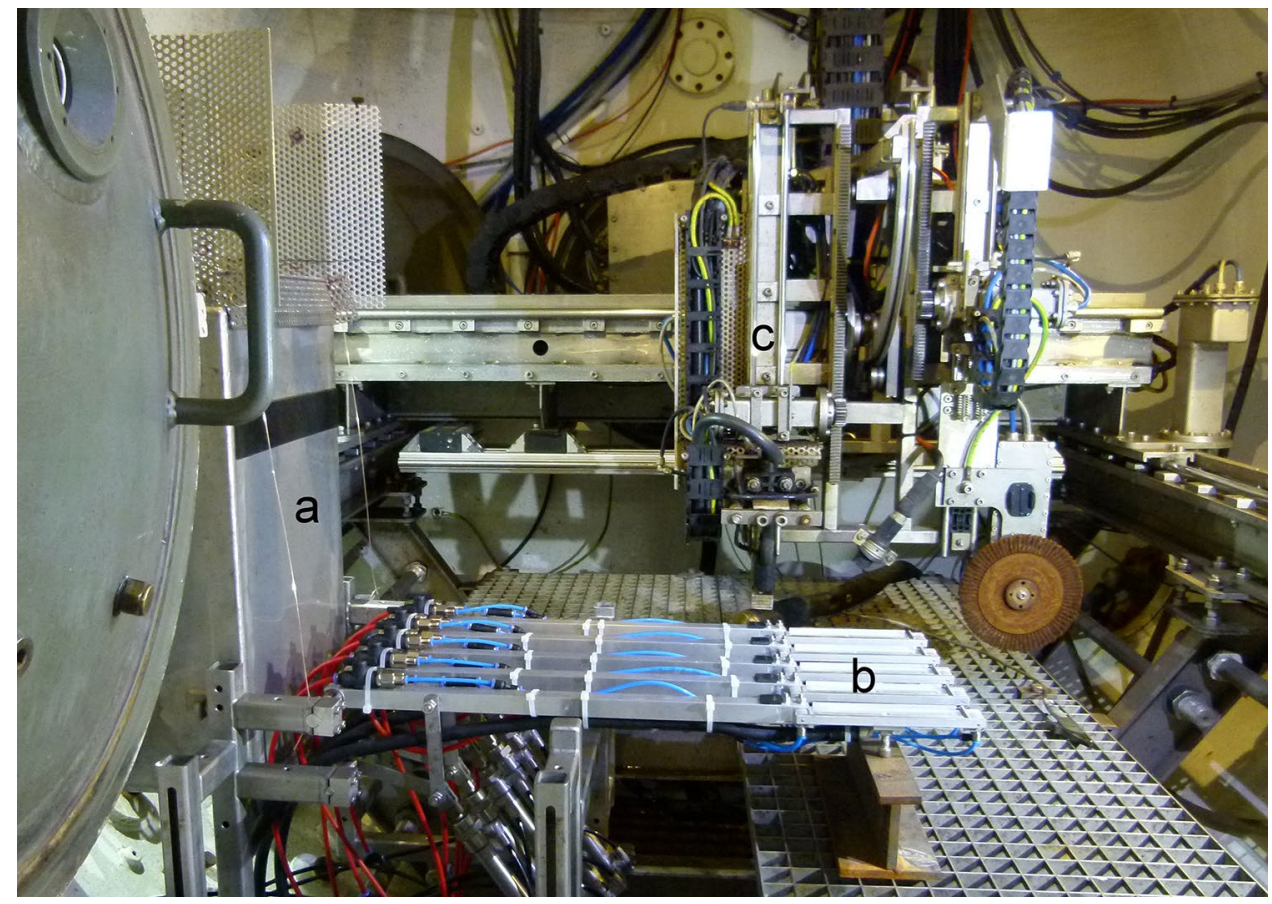

was performed. No significant correlation was found $(p>0.05)$. To meet the strict requirements of the standard, an insulated tank containing $0.2 \mathrm{~m}^{3}$ of liquid nitrogen was installed (Fig. 1a). The height of the tank is designed to ensure $500 \mathrm{~mm}$ of water above the welding samples in the clamping device (Fig. 1b). This way the stick electrode and the electrode holder are fully submerged during the whole welding process. The pneumatic levers are able to convey the welded samples into the liquid nitrogen within $20 \mathrm{~s}$ after the welding process. The pneumatic system allows carrying out wet weldments in different water depths, while meeting the time limits required in ISO 3690, thus ensuring the entrapment of the diffusible hydrogen within the weldments until the measurement is carried out. Cleaning and separating of the samples was performed within $60 \mathrm{~s}$. If this was not enough time, the samples were stored in liquid nitrogen again for at least $120 \mathrm{~s}$. After that, the work continued for another $60 \mathrm{~s}$ before cooling again. All samples were marked individually and weighed before welding and after cleaning to determine the mass of deposited weld metal. The samples were analysed using a Bruker G4 Phoenix analyser for diffusible Hydrogen (Fig. 2a). This analyser uses the carrier gas hot extraction method, and measures the hydrogen content with a sensitive and long-term stable thermal conductivity detector. The residual hydrogen was determined using a LECO TCH 600 analyser (Fig. 2b). This measures the extracted hydrogen in a carrier gas (helium) by infrared absorption after melting the sample in the inert gas atmosphere.

\subsection{Experimental procedure}

Weldments were carried out in simulated water-depths of $5,20,40$, and $60 \mathrm{~m}$. The base material was S235 JR structural steel with a carbon equivalent (CE) of 0.35 . Four different types of stick electrodes were used,
Fig. 2 The Hydrogen analysers used: a Bruker G4 Phoenix analyser for diffusible Hydrogen, b LECO TCH 600 analyser for hydrogen, nitrogen and oxygen

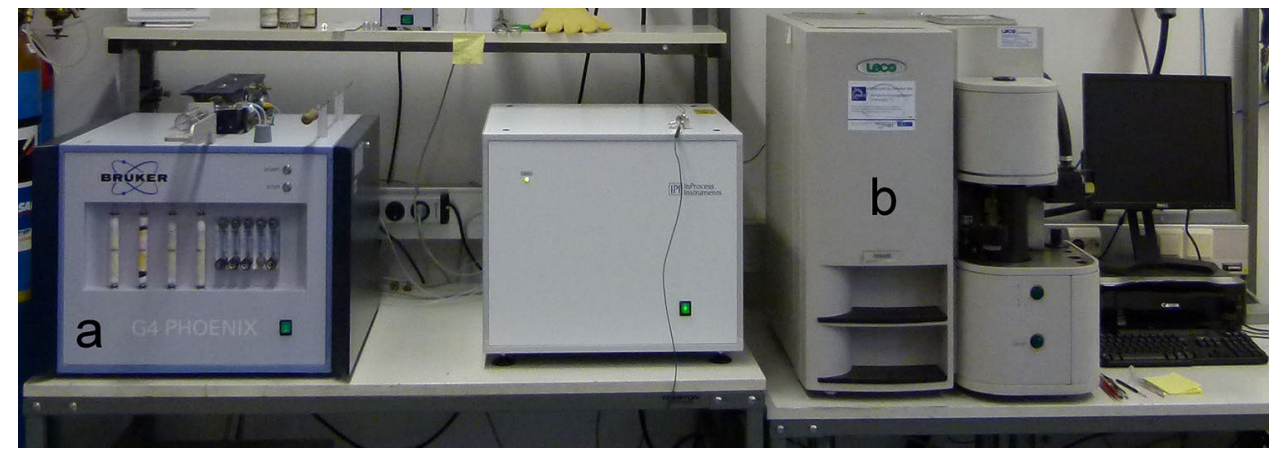

SN Applied Sciences a SPRINGER NATURE journa 


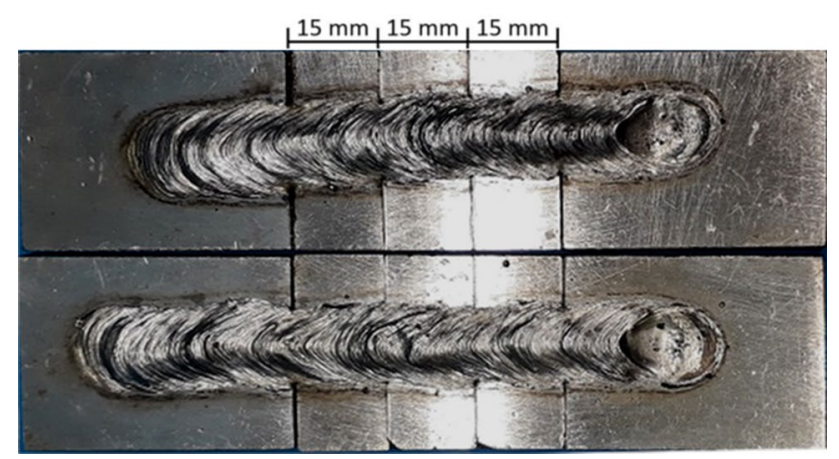

Fig. 3 Wet welded samples based on ISO 3690—sample geometry C

Table 1 Composition of the electrodes' coatings (in wt.-\%)

\begin{tabular}{lllll}
\hline Electrode designation & $\mathrm{HK}-3$ & $\mathrm{HK}-6$ & $\mathrm{HK}-9$ & $\mathrm{HK}-25$ \\
\hline $\mathrm{CaCO}_{3}$ & 20 & 20 & 20 & 20 \\
$\mathrm{FeMn}$ & 10 & 10 & 10 & 12 \\
$\mathrm{Fe}$ & 1 & 1 & 1 & 1 \\
$\mathrm{TiO}_{2}$ & 53 & 55 & 51 & 51 \\
$\mathrm{Al}_{4}(\mathrm{OH})_{8}\left[\mathrm{Si}_{4} \mathrm{O}_{10}\right]$ & 2 & 2 & 2 & 2 \\
$\mathrm{C}_{6} \mathrm{H}_{10} \mathrm{O}_{5}$ & 2 & 0 & 4 & 2 \\
$\mathrm{SiO}_{2}$ & 12 & 12 & 12 & 12 \\
$\mathrm{Total}$ & 100 & 100 & 100 & 100 \\
\hline
\end{tabular}

resulting in $n=390$ evaluable weldment samples according to ISO 3690-sample geometry C (3 samples per weldment, each one $10 \mathrm{~mm} \times 15 \mathrm{~mm} \times 30 \mathrm{~mm}$, Fig. 3).

The electrodes used were rutile based flux coated stick ones with $\varnothing 3.25 \mathrm{~mm}$. The ferritic steel wire $(0.05 \%$ C, $0.25 \% \mathrm{Si}, 0.5 \% \mathrm{Mn}, 0.5 \% \mathrm{Mo}$ ) had a $\varnothing 5.5 \mathrm{~mm}$ flux coating and an additional waterproof coating. They were produced and provided for this project by Kjellberg Finsterwalde Elektroden und Zusatzwerkstoffe $\mathrm{GmbH}$. The compositions of the electrodes coating are given in Table 1. The main difference is the content of cellulose $\left(\mathrm{C}_{6} \mathrm{H}_{10} \mathrm{O}_{5}\right)$ to vary the development of shielding gas without affecting the slag formation. The electrodes HK3 and HK25 contain the same amount of cellulose, but differ in their FeMn-content to investigate the influence of the alloying element manganese.

In a first step, preliminary welding parameters for each electrode and the selected water depth were identified. It turned out that using different parameters for each type of test noticeably improved the welding quality. This approach avoided inclusion of low quality weldments (e.g. excessive pores, inconsistent or uneven weld bead structure) in the data, which would have biased the analysis. The electrode HK25 allowed a wide range in welding target voltage without degrading welding quality. Thus, this electrode was used with two different target voltages at all depths to evaluate the influence of the arc length (= arc voltage) on the diffusible hydrogen content. For the $5 \mathrm{~m}$ water depth case, the welding current was varied as well. For this electrode the actual voltage between the arc and the work piece and the actual welding current were measured. This was done using the ANALYSATOR HANNOVER system, which enables the measurement, recording, and statistical evaluation of the actual welding current $I$ and the actual arc voltage $U$. The measurement time was $10 \mathrm{~s}$ and the sampling rate $10 \mathrm{kHz}$. After welding the transient signals recorded within $10 \mathrm{~s}$ of the stable process were separated into classes and the most frequent class was treated as the mean value for the whole process. The parameters used for the welding processes are listed in Table 2. The welding results for the selected parameters can be found in the Appendix, Figs. 10, 11, 12 and 13. For the electrode HK25 the results of the weldments with the lower respective voltages are displayed.

Within $20 \mathrm{~s}$ after weldment all samples were stored in liquid nitrogen for further analysis. All conditions regarding the time limits were maintained according to ISO 3690 (e.g. $20 \pm 2 \mathrm{~s}$ between the end of the welding process and the storage in liquid nitrogen, less than 60 s out of cooling for cleaning of the samples). The hot extraction analysis for diffusible hydrogen was performed by heating the samples at a temperature of $400{ }^{\circ} \mathrm{C}$ for $30 \mathrm{~min}$.

After cooling, small samples were taken from the weld metal (Fig. 4), using abrasive waterjet cutting. No time limitation was necessary for this preparation, since diffusion of the residual hydrogen is negligible. These samples were then melted inside the LECO TCH 600 in order to measure the

Table 2 Targeted welding parameters

\begin{tabular}{llllllll}
\hline Water depth & HK3, 6,9 & All electrodes & HK3 & HK6 & HK9 & \multicolumn{2}{l}{ HK25 } \\
\cline { 5 - 7 } & Target current $(\mathrm{A})$ & Welding speed & Target voltage $(\mathrm{V})$ & & Target current (A) & Target voltage (V) \\
\hline $5 \mathrm{~m}$ & 200 & $0.18 \mathrm{~m} / \mathrm{min}(3 \mathrm{~mm} / \mathrm{s})$ & 22 & 21.8 & 21.2 & $160 / 200$ & $22 / 23$ \\
$20 \mathrm{~m}$ & 200 & $0.18 \mathrm{~m} / \mathrm{min}$ & 22 & 21.8 & 22.2 & 200 & $22 / 24$ \\
$40 \mathrm{~m}$ & 200 & $0.18 \mathrm{~m} / \mathrm{min}$ & 22 & 20.8 & 21.2 & 200 & $21 / 23.5$ \\
$60 \mathrm{~m}$ & 200 & $0.18 \mathrm{~m} / \mathrm{min}$ & 22 & 20.8 & 21.2 & 200 & $21 / 23.5$ \\
\hline
\end{tabular}




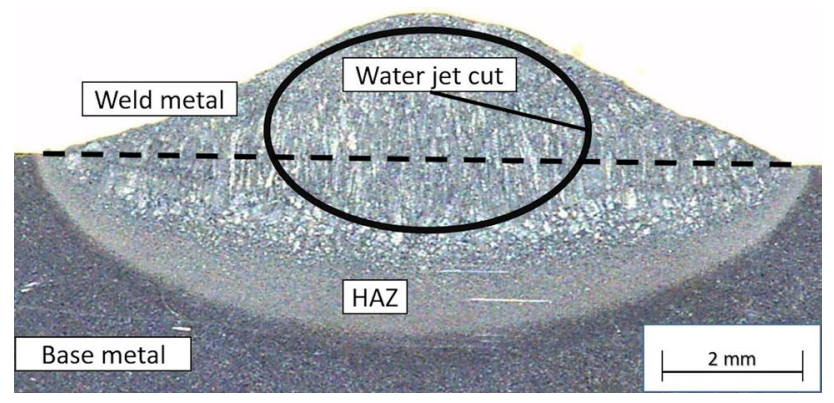

Fig. 4 Macrograph of a weld sample with a schematic representation of the elliptical samples taken from the weld metal; the dotted line represents the border between the molten base metal (below), and the deposited weld metal (above)

residual hydrogen trapped in the samples. A total of $n=83$ samples were analysed regarding their residual hydrogen content. For the diffusible hydrogen $n=390$ samples were analysed.

\subsection{Statistical methods}

The welded samples were examined as a whole for outliers regarding the diffusible hydrogen content $\left(H_{\mathrm{D}}\right)$. Outliers were defined as values above 1.5 interquartile range in accordance to Tukey's boxplot-method. The remaining values $(n=373)$ were tested for normal distribution of mass of weld deposit $\left(m_{\mathrm{S}}\right)$ and $H_{\mathrm{D}}$ using the Shapiro-Wilk test [24]. Pearson's product moment correlation test was used on $H_{\mathrm{D}}$ and $m_{\mathrm{S}}$ and Kendall's Tau $(\tau)$ was used for correlations regarding not normally distributed variables like the water depth $(d)$, the welding current $(I)$ and the arc voltage $(U)$. Not normal distributed sets of data were compared using the Mann-Whitney U-test. Regression models were fitted using the least squares linear regression method. For nonlinear terms orthogonal variables were used to prevent collinearities. In order to identify variables significantly influencing $H_{D}$ and reduce non-influential variables, stepwise bi-directional selection of variables in multivariate linear regression analyses was performed based on the exact Akaike information criterion (AIC), for each Electrode separately. In case the AIC-selected model did include non-significant variables, an analysis of variance (ANOVA) for multiple model fits was calculated and the final model was eventually chosen comparing homoscedasticity, distribution of residuals, influential cases, and the adjusted $R^{2} \mathrm{~s}$.

\section{Results}

\subsection{Diffusible hydrogen}

The statistical evaluations showed that the diffusible hydrogen content $H_{\mathrm{D}}$ and the mass of weld deposit $m_{S}$ are normally distributed for all electrodes at every water depth. The individual results of the diffusible hydrogen content for each electrode and depth are shown in Fig. 5. A significant correlation was noticed between $m_{\mathrm{S}}$ and $H_{\mathrm{D}}$ $(r=-0.58, p \ll 0.001$, Fig. 6) for the whole record as well as every single electrode $(p \ll 0.001)$. The depth $d$ and $H_{D}$ showed a statistical significant negative correlation for the electrodes HK6 (HK6: $\tau=-0.43, p \ll 0.001$ ) and HK9 $(\tau=-0.63, p \ll 0.001)$. The electrode HK3 showed no significant correlation between $d$ and $H_{\mathrm{D}}(\tau=-0.18, p=0.15)$, while electrode HK25 showed only minimal positive correlation ( $\tau=0.15, p \ll 0.001)$.

Since the correlation between $m_{\mathrm{S}}$ and $H_{\mathrm{D}}$ could influence the correlation between $d$ and $H_{D}$, linear regression models for $H_{\mathrm{D}}$ including $m_{\mathrm{S}}$ as well as $d$ were fitted for all electrodes. For the electrode HK25, the measured values of the arc voltage $U$ and the welding current / were included.

The general regression model is:

$H_{\mathrm{D}}\left(m_{\mathrm{S}}, d, U, I\right)=b_{0}+b_{1} * m_{\mathrm{S}}+b_{2} * d+b_{3} * U+b_{4} * I$

The regression models selected for each electrode, using stepwise model selection by the Akaike information criterion, are:

For HK $3(n=35): H_{\mathrm{D}-\mathrm{HK} 3}\left(m_{\mathrm{S}}\right)=b_{0}+b_{1} * m_{\mathrm{S}}$

For HK6 $(n=41): H_{\mathrm{D}-\mathrm{HK} 6}\left(m_{\mathrm{S}}, d\right)=b_{0}+b_{1} * m_{\mathrm{S}}+b_{2} * d$

For HK9 $(n=33): H_{\mathrm{D}-\mathrm{HK} 9}\left(m_{\mathrm{S}}, d\right)=b_{0}+b_{1} * m_{\mathrm{S}}+b_{2} * d$

For HK25 $(n=264): H_{\mathrm{D}-\mathrm{HK} 25}\left(m_{\mathrm{S}}, U, I\right)$

$$
=b_{0}+b_{1} * m_{\mathrm{S}}+b_{3} * U+b_{4} * I
$$

The regressions coefficients for each model are listed in Table 3.

For the electrode HK3 and HK25 no significant influence of water depth $d$ could be found. The linear model of HK25 shows a significant influence of the arc voltage and welding current. The models explain 51\% (HK3) and 44\% (HK25) of the variance in $H_{D}$.

The electrodes HK6 and HK9 showed a significant influence of $d$ and $m_{\mathrm{S}}(p<0.001)$.

The models explain $85 \%$ (HK6) and $77 \%$ (HK9) of the variance in $H_{D}$. 
Fig. 5 Boxplots of the diffusible hydrogen contents in the deposited weld metal at the four different water depths for all 4 electrodes (HK25 represents all the results of this electrode, regardless of the targeted voltages); the horizontal line within the boxes represents the median, the boxes represent the interquartile rang. The whiskers show the maximum or minimum of each distribution, provided that they do not deviate more than 1.5 times the interquartile distance from the box (the closest quartile)

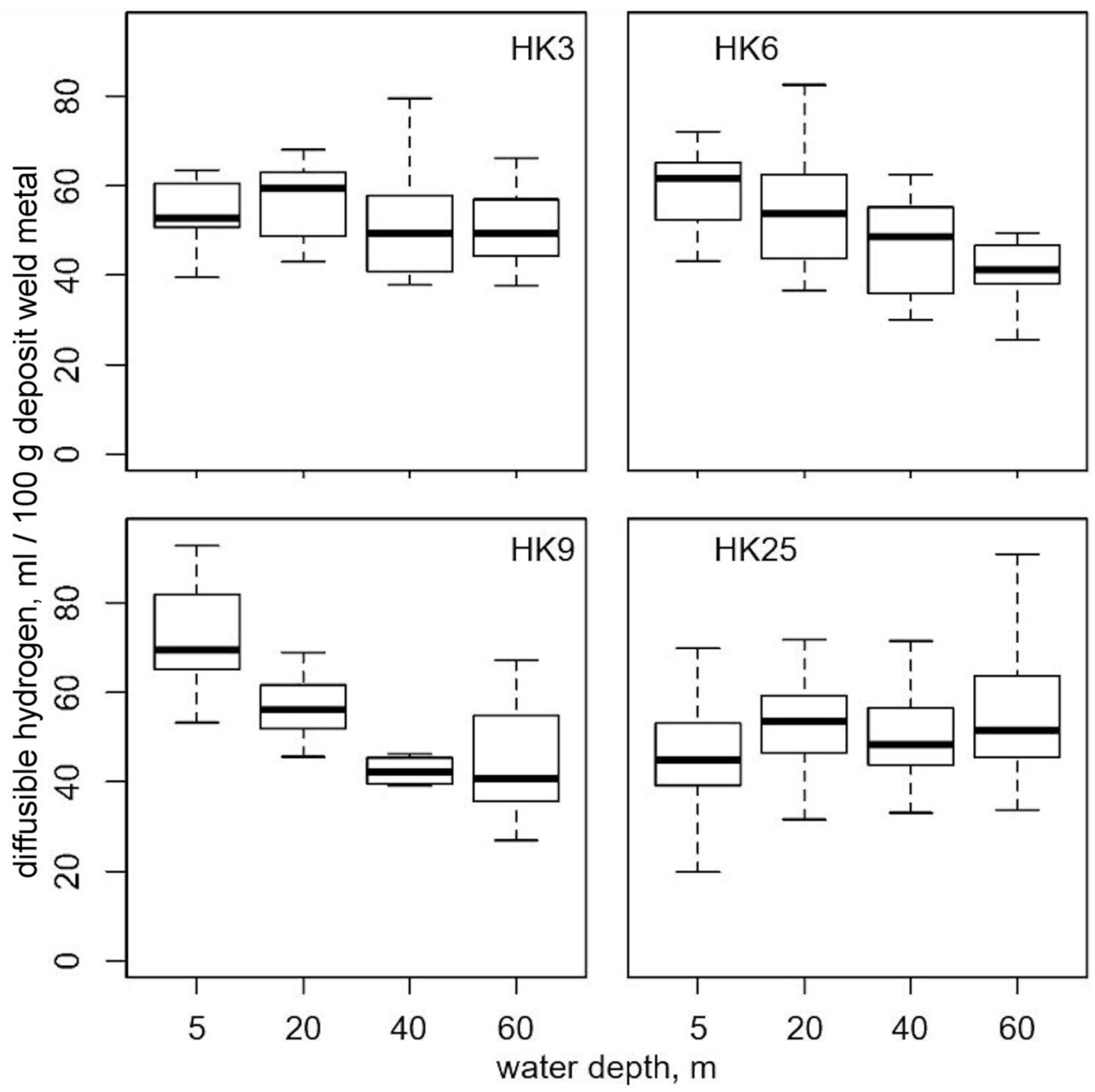

Since $H_{\mathrm{D}}$ was only dependent on $d$ for HK6 and HK9, a general model for the two electrodes was calculated in the same way as before but with an additional variable (cellulose content $=c$ ):

\subsection{Residual hydrogen}

The results of the analysis of the residual hydrogen content showed the same tendencies with all electrodes.

For HK6 and HK9 $(n=74): H_{\mathrm{D}-\mathrm{HK} 6 \& 9}\left(m_{\mathrm{S}}, d, c\right)=b_{0}+b_{1} * m_{\mathrm{S}}+b_{2} * d+b_{3} * c$

The model was adjusted by adding the mean mass of deposited weld metal of each test into the regression model (6). The calculated correlations between $d$ and $H_{\mathrm{D}}$ for the electrodes HK6 and HK9 are shown in Fig. 7.

The cellulose content $c$ had a significant but relatively small effect on the diffusible hydrogen content, regardless of the water depth. In this model the influence of $c$ could be interpreted as a shift to a higher diffusible hydrogen content $H_{\mathrm{D}}$ with an increased content of cellulose $c$, regardless of the depth.
Figure 8 displays the results for the electrode HK25. It can be seen that the residually stored hydrogen content $\left(H_{R}\right)$ tendentially rises with increasing water depth. However, the boxplot shows that the variance rises, too. The boxes are overlapping significantly. The Mann-WhitneyU-Test for unpaired nonparametric samples revealed that a significant difference between the residual hydrogen contents at the consequent depths was not present. The difference between the contents in $5 \mathrm{~m}$ and $60 \mathrm{~m}$ was significant though $(p<0.01)$. The correlation between 


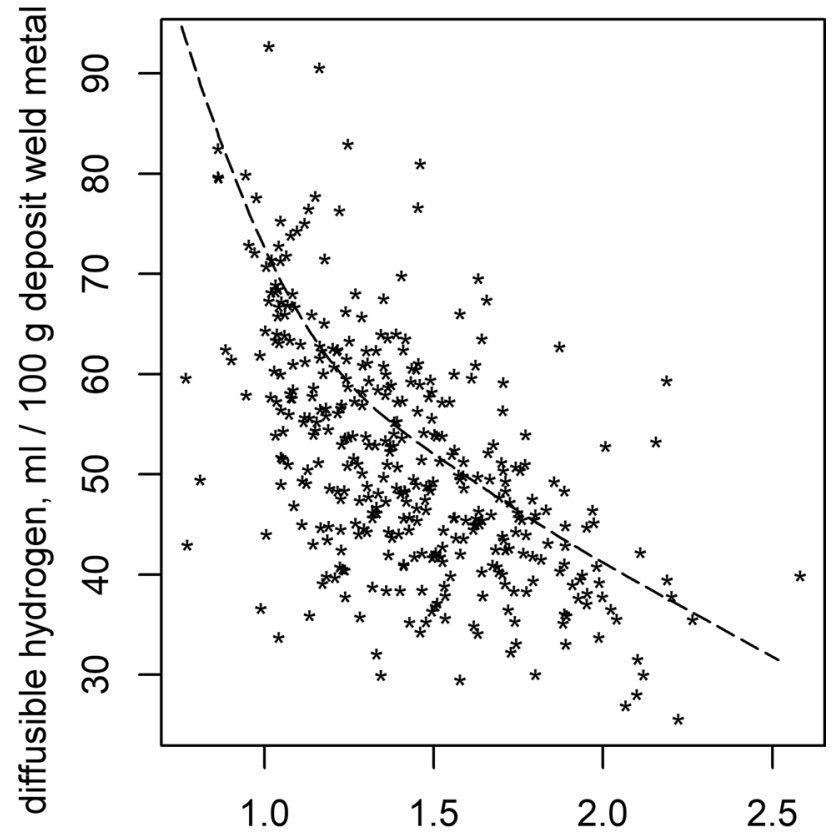

mass of weld deposit, $\mathrm{g}$

Fig. 6 Correlation between diffusible Hydrogen $H_{\mathrm{D}}$ and mass of deposited weld material $m_{\mathrm{S}}$ (all samples)

Table 3 Regression coefficients for each model: $m_{\mathrm{S}}$ is the mass of deposited weld material, $d$ is the water depth, $U$ is the arc voltage, $I$ is the welding current, $c$ is the cellulose content of the electrode; SE stands for standard error

\begin{tabular}{|c|c|c|c|c|c|}
\hline Electrode or variable & $R^{2} /$ adj. $\mathrm{R}^{2}$ & $b_{i}$ & $\mathrm{SE} b_{i}$ & $\beta_{i}$ & $p$ \\
\hline HK3 & $0.51 / 0.49$ & & & & \\
\hline Constant & & 86.99 & 5.88 & & $<0.001$ \\
\hline$m_{\mathrm{S}}(\mathrm{g})$ & & -22.79 & 3.91 & -0.71 & $<0.001$ \\
\hline HK6 & $0.85 / 0.84$ & & & & \\
\hline Constant & & 99.15 & 3.50 & & $<0.001$ \\
\hline$m_{\mathrm{S}}(\mathrm{g})$ & & -25.32 & 2.18 & -0.74 & $<0.001$ \\
\hline$d(\mathrm{~m})$ & & -0.39 & 0.04 & -0.63 & $<0.001$ \\
\hline HK9 & $0.77 / 0.76$ & & & & \\
\hline Constant & & 110.16 & 6.67 & & $<0.001$ \\
\hline$m_{\mathrm{S}}(\mathrm{g})$ & & -25.52 & 4.17 & -0.53 & $<0.001$ \\
\hline$d(\mathrm{~m})$ & & -0.51 & 0.06 & -0.67 & $<0.001$ \\
\hline HK25 & $0.44 / 0.43$ & & & & \\
\hline Constant & & 27.98 & 8.52 & & $<0.001$ \\
\hline$m_{\mathrm{S}}(\mathrm{g})$ & & -23.57 & 1.80 & -0.63 & $<0.001$ \\
\hline$U(\mathrm{~V})$ & & 0.21 & 0.03 & 0.40 & $<0.001$ \\
\hline$I(\mathrm{~A})$ & & 0.58 & 0.19 & 0.16 & $<0.01$ \\
\hline HК6\&9 & $0.79 / 0.77$ & & & & \\
\hline Constant & & 97.86 & 3.47 & & $<0.001$ \\
\hline$m_{\mathrm{S}}(\mathrm{g})$ & & -23.42 & 2.15 & -0.6 & $<0.001$ \\
\hline$d(\mathrm{~m})$ & & -0.43 & 0.04 & -0.62 & $<0.001$ \\
\hline$c(\%)$ & & 1.73 & 0.41 & 0.23 & $<0.001$ \\
\hline
\end{tabular}

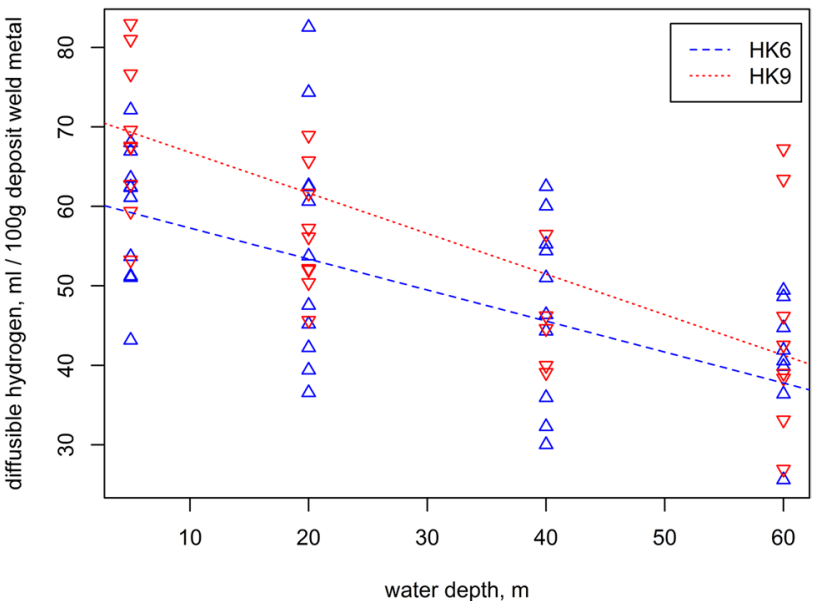

Fig. 7 Adjusted correlation between $d$ and $H_{\mathrm{D}}$ for the electrodes HK6 and HK9 showing a significant influence of depth. The fits are calculated using regression model (6), with the individual mean masses of deposited weld metal and cellulose contents of each electrode

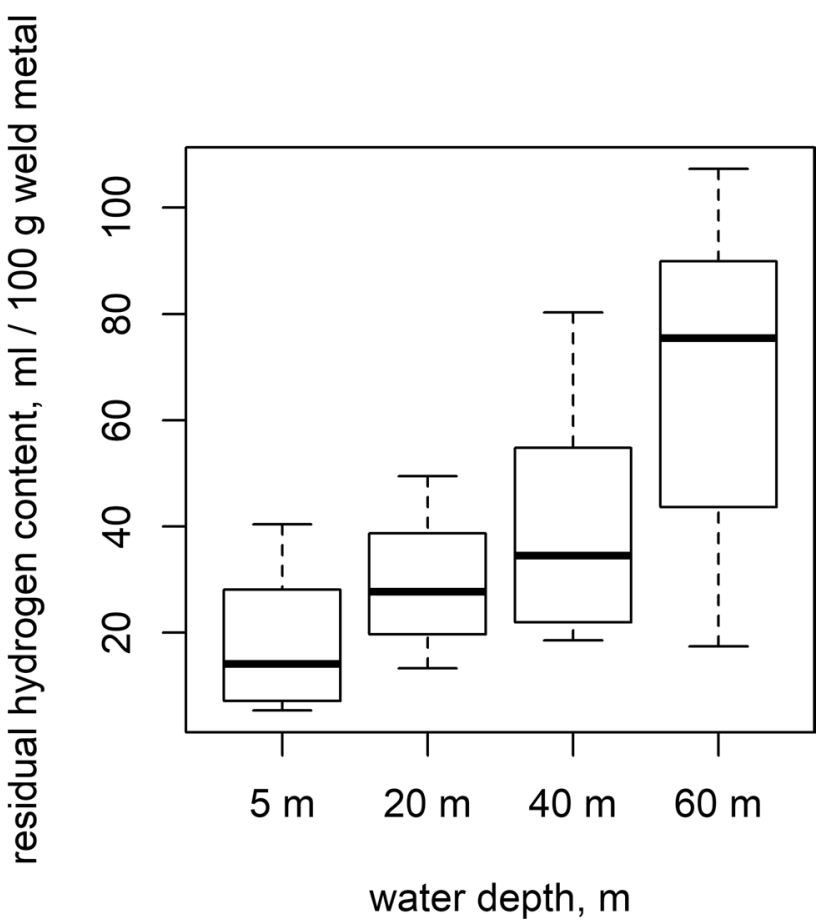

Fig. 8 Correlation between the water depth and the residual hydrogen in the weld metal for electrode HK25

the water depth $d$ and the residual hydrogen $H_{\mathrm{R}}$ was tested using Kendall's correlation tests. The correlations coefficient $\tau$ (Kendall's Tau) was above 0.4 , with a $p$ value below 0.05 , for all electrodes (see Table 4). 
Table 4 Results of the correlation tests of the residual hydrogen content $H_{\mathrm{R}}$ and the water depth $d$

\begin{tabular}{llll}
\hline Electrode & Kendall's Tau $(\tau)$ & $p$-value & $\begin{array}{l}\text { Number } \\
\text { of samples } \\
(n)\end{array}$ \\
\hline HK3 & 0.48 & $<0.05$ & 14 \\
HK6 & 0.52 & $<0.05$ & 18 \\
HK9 & 0.41 & $<0.05$ & 21 \\
HK25 & 0.47 & $<0.05$ & 30 \\
\hline
\end{tabular}

\section{Discussion}

\subsection{Influence of the mass of weld deposit as possible source for error in the measurement of diffusible hydrogen}

A correlation between $m_{\mathrm{S}}$ and $H_{\mathrm{D}}$ is to be expected, considering that the unit of $H_{\mathrm{D}}$ is " $\mathrm{ml} / 100 \mathrm{~g}$ (deposited) weld metal", meaning that the difference in weight before and after welding $\left(m_{\mathrm{S}}\right)$ is used as the reference to standardize the diffusible hydrogen content. In ISO 3690 this standardization is used to get comparable information from different welding processes and sample sizes. During the welding process all molten material, i.e. the droplet as well as the molten base material, will uptake hydrogen, though. However, $H_{\mathrm{D}}$ only considers the deposited material (i.e. the transferred metal droplet). Larger amounts of weld deposit solve more diffusible hydrogen than smaller ones (the correlation of the mass of weld deposit of each sample and the total amount of diffusible hydrogen diffusing out of each sample is significant: $\tau=0.37, p<0.001$ ). If the welding process produces consistent weld beads, the deposited mass will not differ much and the standardization enables a comparison of different stick electrodes, sample sizes or welding methods.

A potential for error lies within the exclusion of the molten base material from the standardizations reference mass. This area (see Fig. 4) does not add any weight, but it is in the liquid phase during the welding process. It will therefore solve diffusible hydrogen during solidification without having influence on the considered mass for standardization. If only little weld metal is deposited, the reference mass for $H_{D}\left(m_{S}\right)$ is small. If the volume of molten base metal is bigger, it solves more hydrogen. However,

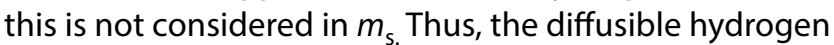
solved in the molten base metal has a high impact on the results, if the mass of deposited weld metal is not constant.

In consistent weld seams, the influence of a variance in deposited weld metal will be insignificant and the penetration will not differ considerable. However, in underwater wet welding the conditions are different. Especially at greater depths the weld bead will hardly be constant enough to obtain equal masses of deposited weld metal in all samples. The reason can be found in the dynamics of the gas bubble surrounding the process zone. It expands and collapses multiple times during the weldment, due to the constant generation of gas caused by the arc [25]. This aspect disturbs the arc and the metal transfer is less constant compared to the dry welding processes [25].

Considering that the deposited mass could differ for different depths, arc voltages, welding currents, and electrodes, and influences $H_{\mathrm{D}}$ as well as the total volume of hydrogen solved in the sample, the mass $m_{\mathrm{S}}$ should be included as a variable when fitting models for linear (or polynomial) regression. This way the influence of $m_{S}$ will not be mistaken for another influence. This is especially important, if the variable of interest is correlated to $m_{s}$.

A more advantageous way to maintain meaningful results would be to measure the real volume of molten material for every sample and then use this volume for standardization. This would imply etching, photographing and measuring (ideally cross sections from both sides of the sample, separately) for every sample. Integrating the influence of the weight into the regression model seems to be the least costly method to obtain feasible results.

\subsection{Influence of depth on the diffusible hydrogen content}

The combined data of the electrodes HK6 and HK9 show a significant negative correlation $(r=-0.62, p<0.001)$ between water depth and diffusible hydrogen (adjusted for the influence of the deposited weld mass). This fits the results of Ando et al. as well as those of da Silva et al. [21, 22]. Since there are only 3 different proportions of cellulose contents in the flux in this record, the cellulose content should be treated as an ordinal variable rather than an interval scaled variable (a prediction of the influence of higher cellulose contents might not be valid). Regarding only $0 \%$ and $4 \%$ of cellulose, the influence can be interpreted as a parallel shift of the regression line to higher hydrogen values for electrode HK9 (4\% cellulose) (Fig. 7). This is understandable as cellulose contains hydrogen. However, the electrodes HK3 and HK25 (2\% cellulose, each) did not show any difference in the diffusible hydrogen content regarding water depth. It seems that there is no general correlation that is accurate for all types of electrodes. It seems, that the diffusible and residual hydrogen content generated by $0-4 \%$ cellulose content in the electrodes flux is rather low compared to the influence of the surrounding water.

The influence of the waters depth could be dependent on the arc characteristics and the general performance of an electrode at a certain depth, rather than on the pressure at the depth itself. In other words: disturbances (variables 
which could not be controlled yet) may have had influence on the diffusible hydrogen, and may themselves have been influenced by the depth of the water.

For all linear models, statistical tests were conducted in order to improve the fits. One method used was a "residuals vs. fits" plot. In the case of the linear model of HK9, this comparison between the residuals (the difference between the observed and the predicted value) and the fitted values (estimated responses) indicated that the model could be improved by the addition of polynomial terms. The full model included $m_{s}, d$, their interaction, and polynomial terms up to the third power. It was subsequently reduced to its significant variables using stepwise bi-directional selection of variables based on the exact Akaike information criterion (AIC) (see Table 5):

$H_{\mathrm{D}-\mathrm{HK} 9-\text { polinomial }}\left(m_{\mathrm{S}}, d\right)=b_{0}+b_{1} * m_{\mathrm{S}}+b_{2} * d+b_{3} * d^{2}$

This model explains $92 \%$ of the variance in $H_{D}$ for electrode HK9 and shows a plateau at a depth of $45 \mathrm{~m}$ after which the hydrogen content does not decrease any further. The boxplot in Fig. 5 (bottom left) illustrates this. The outcome coincides with the observations of da Silva et al. [22], except for a shift to slightly higher depths.

\subsection{Influence of the arc voltage on the diffusible hydrogen content}

The evaluation of the arc voltage recorded during the welding process match the observations of Gao et al. [26] and are contrary to the ones of Świerczyńska et al. [20]. The multivariate linear model over all samples containing information on the arc voltage $(n=264)$ shows a significant $(p<0.01)$ positive effect of the measured arc voltage on $H_{D}$. A longer arc (higher arc voltage) leads to higher hydrogen contents. This reasonable as a larger arc column leads to more ionization, which in turn should result in more solvable hydrogen.

The correlation of arc voltage and diffusible hydrogen content can easily be misjudged, because a correlation between arc voltage and the mass of deposited weld

Table 5 Coefficients of the polynomial regression model for the electrode HK9. $m_{\mathrm{S}}$ is the mass of deposited weld material and $d$ is the water depth: the $\beta_{i}$ values are not stated, because the inclusion of $d^{2}$ leads to collinearities, SE stands for standard error

\begin{tabular}{lrrll}
\hline & $R^{2}$ /adj. $\mathrm{R}^{2}$ & \multicolumn{1}{c}{$b_{i}$} & $\mathrm{SE} b_{i}$ & $p$ \\
\hline HK9 & $0.92 / 0.91$ & & & \\
Constant & & 126.62 & 4.62 & $<0.001$ \\
$m_{\mathrm{S}}(\mathrm{g})$ & & -28.98 & 2.56 & $<0.001$ \\
$d(\mathrm{~m})$ & & -1.79 & 0.18 & $<0.001$ \\
$d^{2}(\mathrm{~m})$ & & 0.02 & 0 & $<0.001$ \\
\hline
\end{tabular}

metal can be assumed. If the correlation of arc voltage and diffusible hydrogen content is evaluated, without considering the alteration of the mass of deposited weld metal caused by the change of arc voltage, a misinterpretation of effects is likely (see paragraph 4.1). This is why the multivariate linear regression is recommended.

In the case of the electrode HK25, the correlation between $U$ and $H_{\mathrm{D}}$ was tested with small to negative results $(\tau=-0.12 ; p<0.05)$. However, there is also a correlation between $U$ and $m_{\mathrm{S}}(\tau=0.18 ; p \ll 0.05)$. The correlation between $m_{\mathrm{S}}$ and $H_{\mathrm{D}}$ is even more pronounced ( $\tau=-0.56$; $p \ll 0.05)$. This could mean that the longer arc led to more deposited weld metal, which itself led to lower diffusible hydrogen contents $\left(H_{D}\right)$. The possible correlations between water depth, welding current, arc voltage, and deposited weld mass make the bi-directional correlations with the diffusible hydrogen content even more prone to misinterpretation. If all the influencing variables are used to calculate a multivariate model, the variables that do not significantly influence the result can be neglected, while still focusing on the variables that might interact with each other and thus lead to misjudged effects in bi-variate correlation analyses.

The final multivariate linear model for the electrode HK25 (Eq. 5) demonstrates a positive correlation between $U$ and $H_{\mathrm{D}}$. The fact that this is contrary to the result of the two-dimensional bi-variate correlation test highlights the importance of the multivariate regression.

\subsection{Results of the residual hydrogen measurement}

Residual hydrogen was analysed for 83 samples. For all electrodes a positive correlation between water depth and residual hydrogen $H_{R}$ can be found. This is different to the results of da Silva et al. [22], where the residually stored hydrogen content remained the same from 0.3 to $20 \mathrm{~m}$ water depth. It has to be stated that only 2 samples were analysed by da Silva et al., which may explain the difference, because the variance in the residual hydrogen contents might be rather large at higher water depth (Fig. 8).

Considering that the correlation test of $d$ and $H_{R}$ showed positive results for all electrodes while $d$ and $H_{\mathrm{D}}$ are negatively correlated for HK6 and HK9, for these two electrodes both variables were summed up to $H_{T}$, the total amount of hydrogen:

$H_{\mathrm{T}-\mathrm{HK} 6 \& 9}=H_{\mathrm{R}-\mathrm{HK} 6 \& 9}+H_{\mathrm{D}-\mathrm{HK} 6 \& 9}$

$H_{\mathrm{T}}$ was tested negative for correlation with water depth $(\tau=0.02, p=0.9)$. The linear model $H_{\mathrm{T}-\mathrm{HK} 6 \& 9}\left(m_{\mathrm{S}}, d\right)$ showed similar results. A one-way analysis of variance was calculated, showing that there was no significant difference in the means of $H_{\mathrm{T}}$ regarding the different depths $(p=0.48)$. 
This allows to conclude that the total amount of hydrogen stored within the sample did not change significantly with the depth. However, this correlation is only applicable for the electrodes HK6 and HK9.

\subsection{Comparison of the influencing variables}

In an attempt to compare the influences, which the analysed variables have on the diffusible hydrogen content, relative effect sizes were calculated using the multivariate regression models. The results are shown in Fig. 9. The relative effect sizes are suitable for comparing the influence of variables relative to each other, for the respective regression model only.

In all cases the variance in the mass of the deposited weld metal $m_{\mathrm{S}}$ has a huge influence on the diffusible hydrogen content $H_{\mathrm{D}}$. Only in the results of electrode HK9 (and thus in the combined model for HK6 and HK9), the influence of the water depth $d$ has a larger effect on the resulting diffusible hydrogen content than the mass of the deposited weld metal $m_{\mathrm{s}}$. The results of the electrode HK25 show, that the influence of the arc voltage is bigger than the influence of the welding current.

\subsection{Discussion of the experimental method and the statistics}

The present study is the first one using an arc voltage controlled welding machine for automated stick electrode welding in different water depths. The constructed equipment can adhere to the strict time specifications of ISO 3690. The number of samples welded for this study is sufficient to safely use statistical methods to evaluate the results [24].

The results of this study show that the variance in $H_{D}$ is large in the wet welding process. Even in an automated, arc voltage controlled process, where the timespans can be held according to the limits specified in ISO 3690,

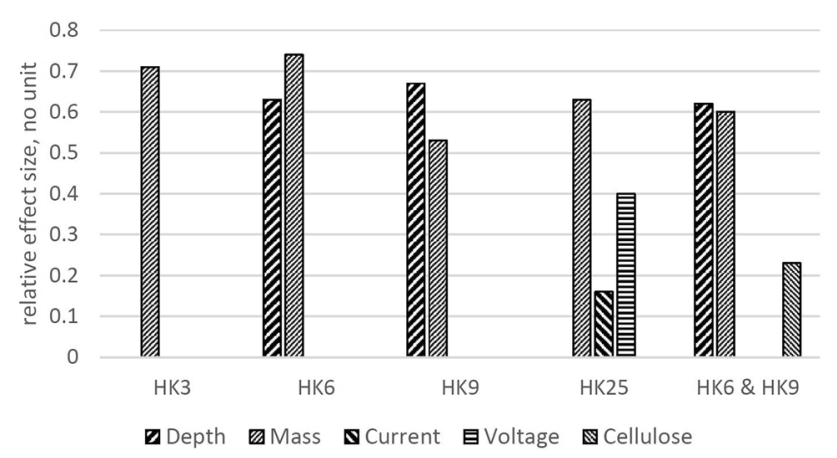

Fig. 9 Relative effect sizes of the different variables for each regression model (only significant effects) many samples are needed to obtain useful, statistically validated results. In 2001 Miles and Shevlin investigated the number of samples needed to gain statistical valid results considering the estimated effect size of the individual predictors [27]. Their results suggest that even more samples might be needed, considering the relatively small estimated effect the predictor variables have on the diffusible hydrogen content in wet welding. The time and effort this would take is enormous.

Not all the correlations and interactions found in this study are understood yet. Some parameters cannot be held constant for different tests. For example: In case of different electrodes and different water depths the electrical settings should be the same to obtain optimal comparability. But if these settings lead to non-optimal welds, the comparability is not given. Thus, the targeted electrical settings must be adjusted, sacrificing equal parameters for quality reasons. Only if enough samples are welded, these small adjustments can be fit into multivariate regression models. These models can be a solid tool to respond to the different electrical settings and account for irregularities like varying masses of deposited weld metal.

\section{Conclusions}

There is no limit of diffusible hydrogen for wet welding defined yet. To assess the risk, which arises from the measured hydrogen contents, is a challenge. The values stated in standards (e.g. AWS D1.1-2000) as maximum hydrogen contents for dry welding were exceeded by every single sample in this study. The study gives an overview of the value range to be expected for the different variables. It can be used as a foundation for further systematic research.

The main findings can be summarized as:

A significant negative correlation between the mass of deposited weld metal and the diffusible hydrogen content was found. The deposited metal and the molten base metal can both solve hydrogen during the welding process. The mass of molten base metal is not considered in the standardization of $H_{D}$, though. If the mass of deposited weld metal is small for one sample, the hydrogen solved in the base metal has a high impact on the results of $H_{D}$, because it is measured as it diffuses out of the sample, but the mass it was solved in is not considered. Instead this volume of diffusible hydrogen is referenced on the mass of the deposited weld metal in the case of $H_{\mathrm{D}}$. In order not to misjudge influences due to this, the mass of deposited weld metal was included as a disturbance variable in all regression models. 
Increasing the water depth leads to higher amounts of residually stored hydrogen $\left(H_{R}\right)$ for all the four tested stick electrodes.

The diffusible hydrogen content $\left(H_{\mathrm{D}}\right)$ decreases in two of the four cases and stays constant for the others two electrodes. In the case of the two electrodes with decreasing diffusible hydrogen content, the total amount of hydrogen within a welded sample $H_{\mathrm{T}}=H_{\mathrm{R}}+H_{\mathrm{D}}$ does not change significantly while varying the water depth.

The arc voltage (arc length) and welding current showed positive correlation with the diffusible hydrogen content. Higher currents lead to more energy input and thus result in a higher amount of dissociated water. Longer arcs lead to larger arc columns, and higher arc temperatures. Hence, more water is in contact to the arc, and can be dissociated. Both lead to an increase of diffusible hydrogen in the weld metal.

The alteration of the cellulose content of the stick electrode coating led to slightly higher diffusible hydrogen contents, regardless of the water depth. This is explained by the hydrogen contained in cellulose.

The study also showed the inconsistency of the wet welding process. A large amount of samples was necessary to gain statistically valid results, even in an automated process. Only high effort and a huge sample size lead to valid reproducible results that can be transferred into the manual application.

Acknowledgements Open Access funding provided by Projekt DEAL.

\section{Compliance with ethical standards}

Conflict of interest The authors declare that they have no conflict of interest.

Open Access This article is licensed under a Creative Commons Attribution 4.0 International License, which permits use, sharing, adaptation, distribution and reproduction in any medium or format, as long as you give appropriate credit to the original author(s) and the source, provide a link to the Creative Commons licence, and indicate if changes were made. The images or other third party material in this article are included in the article's Creative Commons licence, unless indicated otherwise in a credit line to the material. If material is not included in the article's Creative Commons licence and your intended use is not permitted by statutory regulation or exceeds the permitted use, you will need to obtain permission directly from the copyright holder. To view a copy of this licence, visit http://creativecommons .org/licenses/by/4.0/.

\section{Appendix}

See Figs. 10, 11, 12, 13.

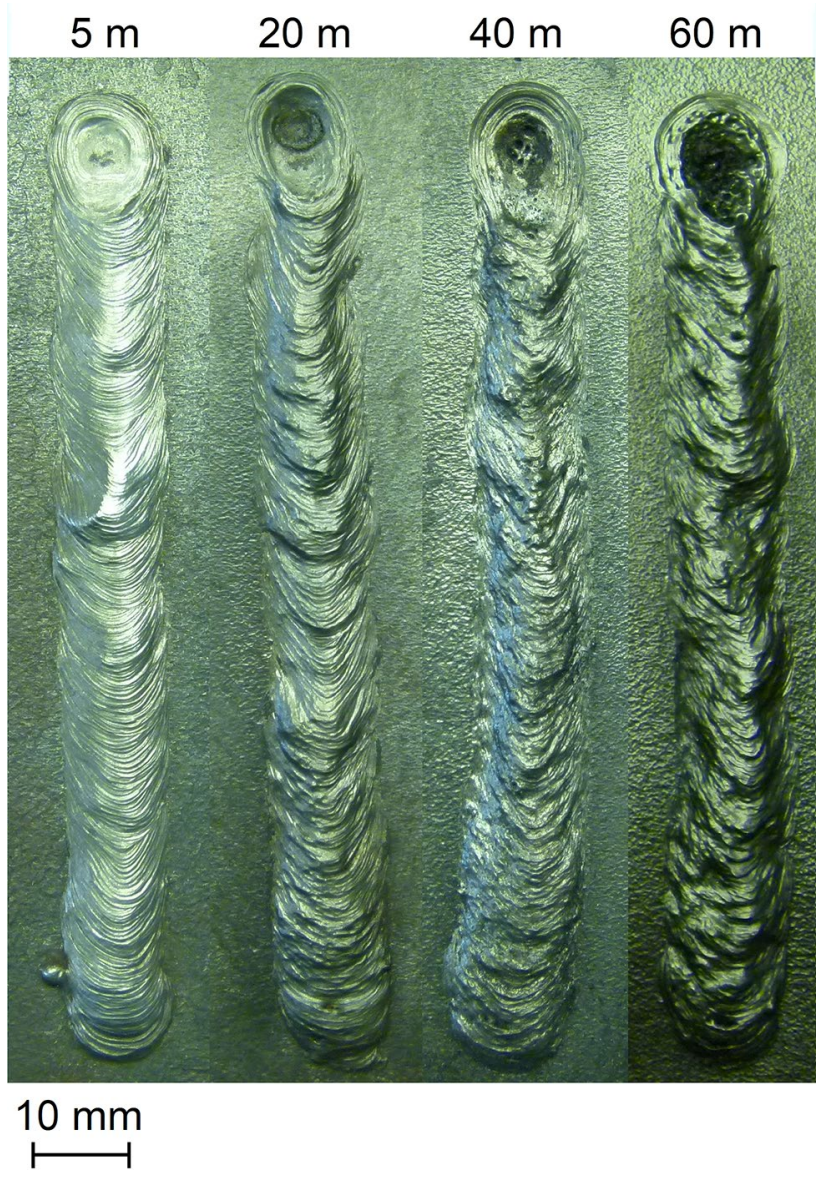

Fig. 10 Bead on plate weld seams welded with the stick electrode $\mathrm{HK} 3$ in the water depth $5 \mathrm{~m}, 20 \mathrm{~m}, 40 \mathrm{~m}$, and $60 \mathrm{~m}$. The parameters used are listed in Table 2 


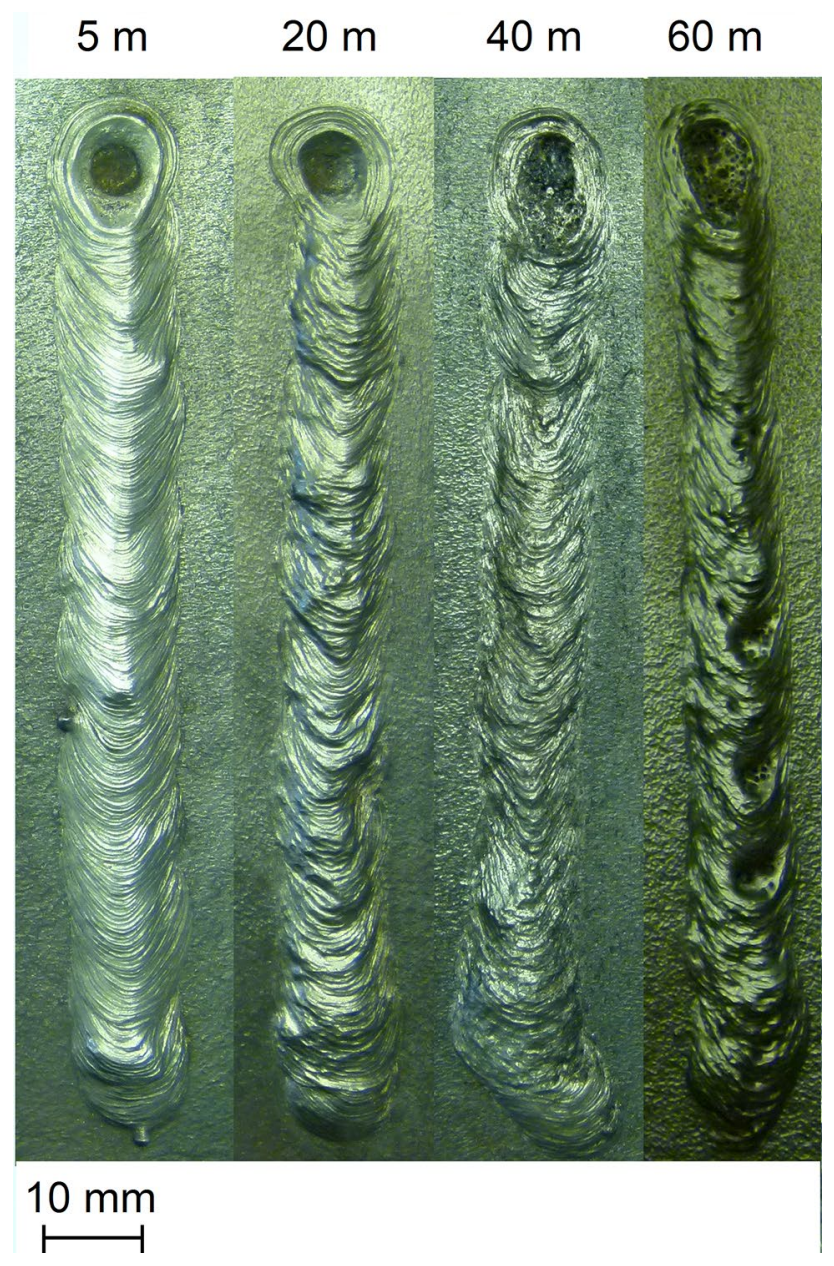

Fig. 11 Bead on plate weld seams welded with the stick electrode HK6 in the water depth $5 \mathrm{~m}, 20 \mathrm{~m}, 40 \mathrm{~m}$, and $60 \mathrm{~m}$. The parameters used are listed in Table 2

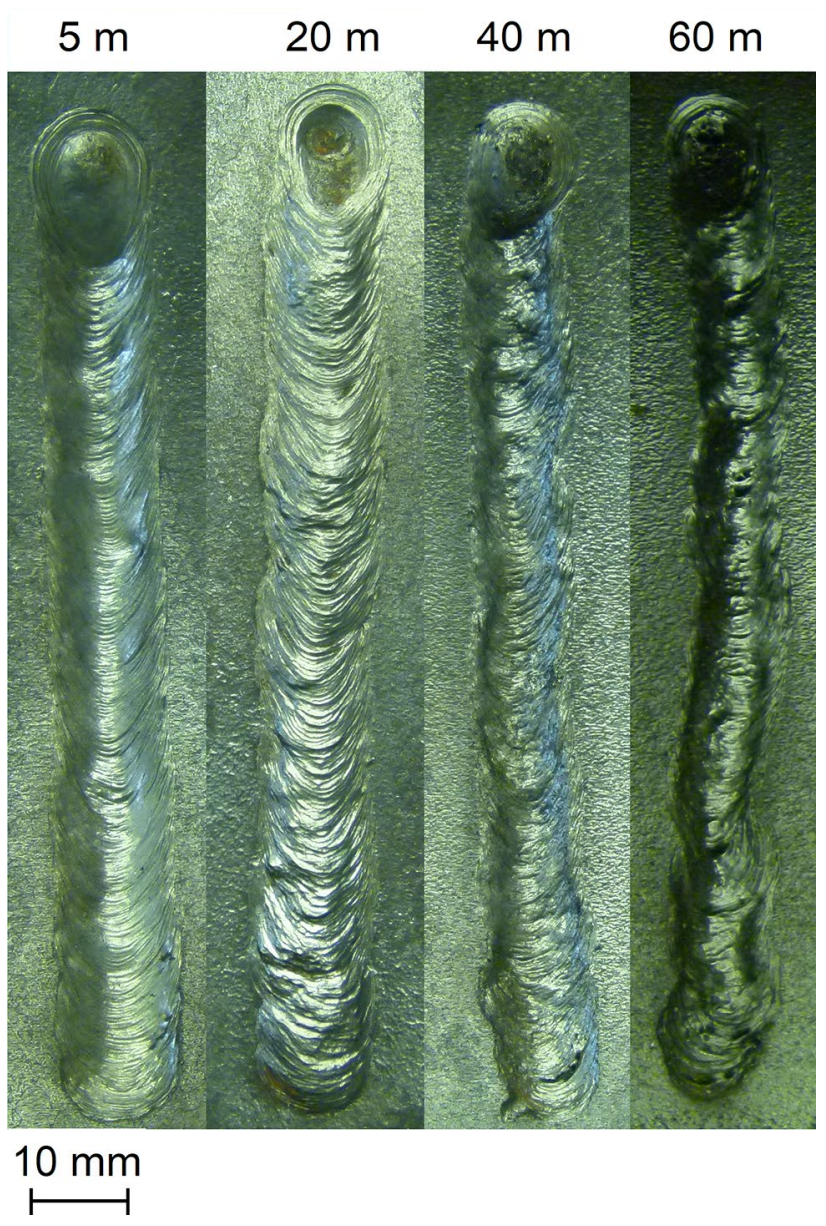

Fig. 12 Bead on plate weld seams welded with the stick electrode HK9 in the water depth $5 \mathrm{~m}, 20 \mathrm{~m}, 40 \mathrm{~m}$, and $60 \mathrm{~m}$. The parameters used are listed in Table 2 


\section{$5 \mathrm{~m} \quad 20 \mathrm{~m} \quad 40 \mathrm{~m} \quad 60 \mathrm{~m}$}

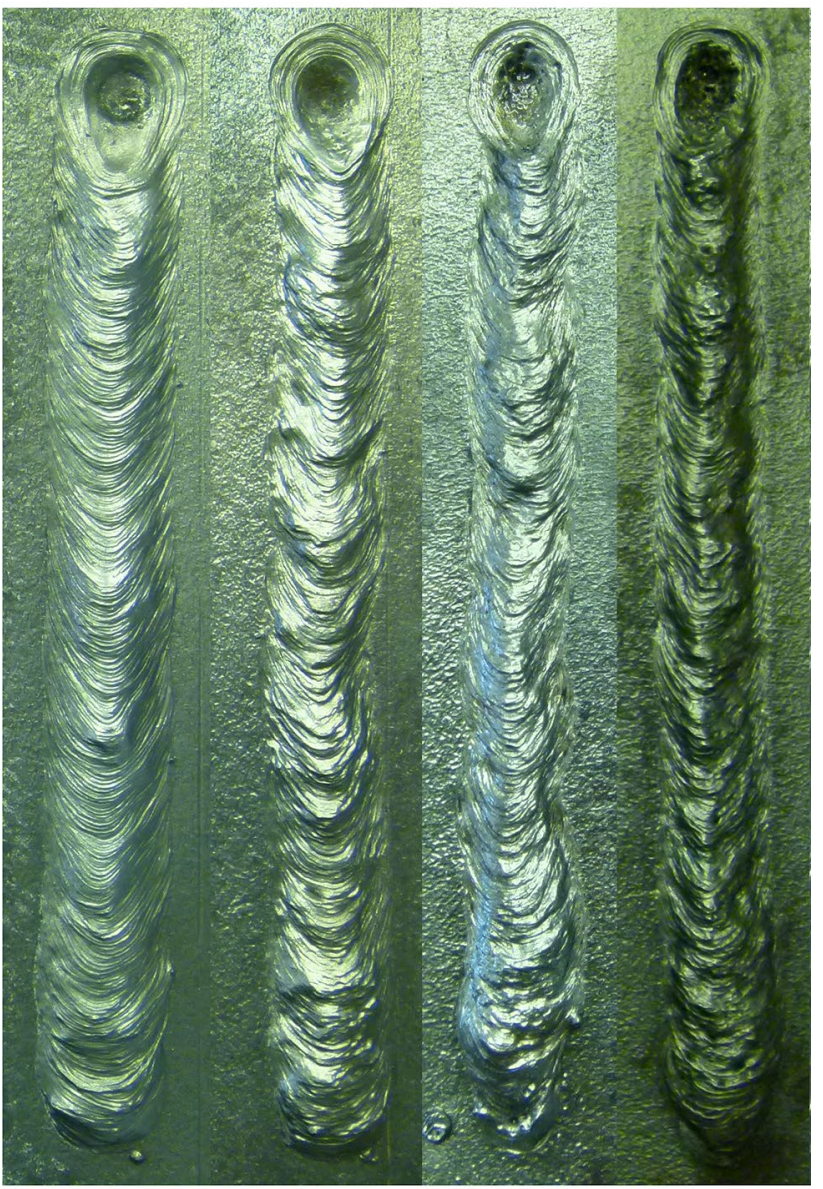

$10 \mathrm{~mm}$

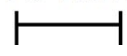

Fig. 13 Bead on plate weld seams welded with the stick electrode HK25 in the water depth $5 \mathrm{~m}, 20 \mathrm{~m}, 40 \mathrm{~m}$, and $60 \mathrm{~m}$. The parameters used are listed in Table 2 (lower value of each parameter)

\section{References}

1. Garašić I, Kralj S, Kožuh Z (2009) Investigation into cold cracking in underwater wet welding of API 5L X70 steel. Trans FAMENA 33(3):25-34

2. Woodtli J, Kieselbach R (2000) Damage due to hydrogen embrittlement and stress corrosion cracking. Eng Fail Anal 7(6):427450. https://doi.org/10.1016/S1350-6307(99)00033-3

3. Bailey N, Coe FR, Gooch TG, Hart PHM (1973) Welding steels without hydrogen cracking. Removing hydrogen during welding and heat treatment. Abington Publishing, Ohio

4. Yushchenko KA, Gretskii YY, Maksimov SY (1997) Study of physicometallurgical peculiarities of wet arc welding of structural steels. In: Papers presented at underwater wet welding and cutting. International seminar and workshop. TWI North, Middlesbrough, UK, 17-18 April 1997, pp 6-30. Woodhead Publishing Ltd, Cambridge, England
5. ASM International (ed) (1990) ASM metals handbook Volume 06. Welding, brazing, and soldering. ASM HandBooks. ASM Intl., Materials Park, Ohio

6. American Welding Society (2015) Structural welding code - Steel. AWS(D1.1/D1.1M:2015). https://www.academia. edu/38613055/AWS_D1.1_D1.1M_2015_An_American_Natio nal_Standard_Structural_Welding_Code_-_Steel_American_ Welding_Society

7. Tomków J, Fydrych D, Rogalski G (2019) Role of bead sequence in underwater welding. Materials 12:3372. https://doi. org/10.3390/ma12203372

8. Tomków J, Rogalski G, Fydrych D (2019) Advantages of the application of the temper bead welding technique during wet welding. Materials. https://doi.org/10.3390/ma12060915

9. Tomków J, Fydrych D, Rogalski G, Łabanowski J (2018) Temper bead welding of $S 460 \mathrm{~N}$ steel in wet welding conditions. Adv Mater Sci. https://doi.org/10.1515/adms-2017-0036

10. Tomków J, Rogalski G, Fydrych D, Łabanowski J (2018) Improvement of S355G10+N steel weldability in water environment by Temper Bead Welding. J Mater Process Technol. https://doi.org/10.1016/j.jmatprotec.2018.06.034

11. Menezes PHR, Pessoa ECP, Bracarense AQ (2019) Comparison of underwater wet welding performed with silicate and polymer agglomerated electrodes. J Mater Process Technol 266:63-72. https://doi.org/10.1016/j.jmatprotec.2018.10.019

12. Santos VR, Monteiro MJ, Rizzo FC, Bracarense AQ, Pessoa ECP, Marinho RR, Vieira LA (2012) Development of an oxyrutile electrode for wet welding. Weld J 12(2012):319-328

13. Klett J, Hassel T (2020) Reducing the risk of hydrogen-induced cold cracks in hyperbaric wet welding of highstrength steels by using austenitic welding consumables. Weld Cut 19(1):54-60

14. Maksimov S (2005) Structure and properties of the austenite weld metal in wet underwater welding of low-alloy higher strength steel. Int Weld Congress IIW-IC 082:1-5

15. Rowe M, Liu S (2001) Recent developments in underwater wet welding. Sci Technol Weld Join 6(6):387-396. https://doi. org/10.1179/stw.2001.6.6.387

16. Li H, Liu D, Song Y, Yan Y, Guo N, Feng J (2017) Microstructure and mechanical properties of underwater wet welded highcarbon-equivalent steel Q460 using austenitic consumables. J Mater Process Technol 249(Supplement C):149-157. https://doi. org/10.1016/j.jmatprotec.2017.06.009

17. Olschok S, Reisgen U (2017) Mechanisch technologische Eigenschaften unterwassergeschweißter hoch- und höherfester Stähle. Schlussbericht zu IGF-Vorhaben Nr. 18.158 N. ISF, RWTH Aachen, Aachen. Accessed 13 Dec 2018

18. Brätz O, Henkel K-M, Klett J, Hassel T (2018) Anwendung der Induktion für schweißtechnische Erwärmung beim nassen Lichtbogenhandschweißen unter Wasser. Kolloquium Induktionserwärmung in der schweißtechnischen Fertigung, Halle (Saale) 2:29-35

19. Zhang HT, Dai $X Y$, Feng JC, Hu LL (2015) Preliminary investigation on real-time induction heating-assisted underwater wet welding. Weld J 94(1):8s-15s

20. Świerczyńska A, Fydrych D, Rogalski G (2017) Diffusible hydrogen management in underwater wet self-shielded flux cored arc welding. Int J Hydrog Energy 42(38):24532-24540

21. Ando S, Asahina T (1983) A study on the metallurgical properties of steel welds with underwater gravity welding. In: IIW (ed) Underwater welding. Proceedings of the international conference held at Trondheim, Norway, 27-28 June 1983 under the auspices of the International Institute of Welding, pp 255-261. Published on behalf of the International Institute of Welding by Pergamon, Oxford 
22. da Silva WCD, Ribeiro LF, Bracarense AQ, Pessoa ECP (2012) Effect of the hydrostatic pressure in the diffusible hydrogen at the underwater wet welding. In: ASME 2012 31st international conference on ocean, offshore and arctic engineering OMAE2012-83002 (44939), 1-8. https://doi.org/10.1115/ OMAE2012-83002

23. International Organization for Standardization (2018) Welding and allied processes-determination of hydrogen content in arc weld metal. Beuth Verlag $\mathrm{GmbH}$, Berlin

24. Field A, Miles J, Field Z (2012) Discovering statistics using R. SAGE Publications, London

25. Wang J, Sun Q, Zhang T, Tao X, Jin P, Feng J (2019) Arc stability indexes evaluation of ultrasonic wave-assisted underwater FCAW using electrical signal analysis. Int J Adv Manuf Technol 103:2593-2608. https://doi.org/10.1007/s00170-019-03463-1
26. Gao W, Wang D, Cheng F, Di X, Deng C, Xu W (2016) Microstructural and mechanical performance of underwater wet welded S355 steel. J Mater Process Technol 238:333-340. https://doi. org/10.1016/j.jmatprotec.2016.07.039

27. Miles J, Shevlin M (2001) Applying regression and correlation: a guide for students and researchers. SAGE Publications, Thousand Oaks

Publisher's Note Springer Nature remains neutral with regard to jurisdictional claims in published maps and institutional affiliations. 